\title{
SHARP POWER AND DIGITAL SURVEILLANCE: THE NEW COGNITIVE WAR
}

\author{
Fiammetta Ricci \\ Professor, Università di Teramo, Italy \\ fricci@unite.it
}

\begin{abstract}
To the new forms of conflict taking place in the world correspond, or are linked, new forms of power: from cognitive warfare to sharp power, up to what is now called surveillance capitalism. Through cognitive conflict and sharp power strategies, we are witnessing an epochal change, an IT revolution that brings political conflict into a digital dimension, which acts on the ground of public opinion, politics and economics; but even more subtly it acts in the control and conditioning of knowledge, of our world view and of facts. The general objective, from a political philosophy and communication ethics point of view, is to understand what changes are taking place and the purposes of controlling information, the conditioning of knowledge, the power of world markets and economic forces, which can be destructive as weapons of war: they can affect the strength of moral and collective resistance of a people, the reputation of a head of state, can pollute information for the failure of diplomatic operations, etc. How can one find adequate tools for cognitive response, autonomy of judgment and decision, exercise of freedom, protection of rights, in particular those of the most fragile social groups who are also the most affected by the new forms of power and unconventional conflict? The aim of my work will be to analyze forms, methods and languages of this interweaving of knowledge conditioning, digital market control, power (political and social), and global competitiveness.
\end{abstract}

Keywords: Power, Cognitive war, Digital surveillance, Global Politics, Democracy

\section{Introduction}

The new forms of digital control (economic, political, capitalist monopolies or large data and information processing agencies) now acting in the world correspond, or are linked, to new forms of power: cognitive warfare, sharp power, data dictatorship and digital surveillance capitalism not only paint the picture of a new way of doing information in cyberspace; but above all they represent new means and new purposes of making politics in the theatre of international relations.

Through cognitive conflict and "sharp power" strategies, we are witnessing an epochal change, a digital revolution that brings the dynamics and political space, both of the internal dialogue of democratic states and in international relations, in a digital dimension, which acts on the ground of public opinion, politics and economy; but even more subtly it acts on the control and conditioning of knowledge, of our 
view of the world, of facts and principles that drive us to act in a way rather than in another.

The overall objective, from a political philosophy and communication ethics perspective, is understanding what are the changes taking place and the purposes of controlling information, conditioning of knowledge, the power of world markets and economic forces, which can be destructive as weapons of war, or at least can be used to change the behaviour, decisions and choices of citizens: they can affect the moral and collective strength of a people, the reputation of a head of state, pollute information for the failure of diplomatic operations, etc.

It is evident to everyone how the advent of the internet, a tool of global and planetary communication, has changed and amplified the scope of influence operations and the information/disinformation processes that run on the web in real time.

But now the asymmetrical competition between systems, governments or large monopolies as a cognitive conflict is no longer just a war of technology but a control of the systems of formation of needs, demands, legitimization, liking or freezing of attention on the life and system of government of our democracies.

Democracy is certainly an open system (always imperfect and evolving), but it is also a source of accountability: it is the task of citizens and the ruling classes to manage the outcomes of technological innovation in the best way.

Analyzing forms, methods and languages of this intertwining of knowledge conditioning, digital control of markets, power (political and social), and global competitiveness, is a fundamental goal for our time.

Some main questions can guide us in this analysis: how is the Internet changing the public sphere, political choices, decisions and democracy? Is the web the place of free and autonomous information, or are information being organized around new centres of power?

How can we find adequate tools for cognitive response, autonomy of judgment and decision-making, exercise of freedom, of protection of rights, especially those of the most fragile social groups who are also the most affected by new forms of power and unconventional conflict?

What kind of control of power (economic, political, financial) can be carried out? What role do the big platforms or tech agencies play for the life of democracy, and especially for the lives of the citizens of a democracy?

Are we sufficiently aware and informed of what is happening through us and despite our acceptance and consent? Are we sufficiently prepared to govern the great Leviathans of world capitalism?

The large agencies that collect, analyze and work Big Data, how, how much and why are considered the big modifiers of the behaviors of individuals and therefore of governments?

Political philosophy, faced with these processes, registers the end of metaphysics as the end of truths that can to be understood in a compact system, and is oriented on 
democratic choices of pluralism and renunciation of one only truth ${ }^{1}$.

But politics without truth runs great risks of becoming despotic in many respects. And it risks falling into despotic forms within democratic societies itself.

The data dictatorship, which Brittany Kaiser deals with, shows new forms of digital despotism that must lead us to ask the question: why do we think what we think? And who decides what we decide?

What is now called the dictatorship of data ${ }^{2}$, and capitalism of digital surveillance ${ }^{3}$, show new forms of despotism and manipulation of individuals on a global scale that must lead us to ask the question: why do we think what we think? And who decides what we decide?

I would therefore like to focus on the forms of digital control not only of Information that runs in a planetary way on the web; but I would also like to reflect on the increasingly close and deep relationship between data control and political control, i.e. what are the forms of political power associated with digital control.

Or, using the title of Shoshana Zuboff's book, how does it act and why the digital "surveillance capitalism" in and on contemporary democracies? This question relates to the nature and function of sharp power and to the forms of cognitive conflict used in the new global scenario.

Zuboff's book reveals the most dangerous frontiers of today's capitalism based on deep inequalities between knowledge and power, and offers us a careful and detailed analysis of the digital world and its undemocratic threats, confronting us with the inhumanity of this era. And it invites you to give a name to what's going on, not to be like goldfish in an aquarium who don't wonder what the water is and who feeds them.

A critical scaffolding needs to be developed to examine the great crisis associated with the distorted and manipulative uses of the digital age.

\footnotetext{
${ }^{1}$ Gianni Vattimo, contemporary Italian philosopher, talks about a new relationship between technology and postmodernity: in the postmodern age we are witnessing a transformation of being and of our way of being in the world, which we might call an "ontologia dell'attualità", as a result of processes of rationalisation of society, fragmentation, loss of unity of sense and, consequently, loss of freedom. Information technologies multiply the agencies of interpretation of reality that create our image of the world, generating a weakening of the principle of reality. See, Vattimo G., Nichilismo ed emancipazione, Garzanti, Milano, 2003, p. 28.

${ }^{2}$ Kaiser, B., Targeted: The Cambridge Analytica Whistleblower's Inside Story of How Big Data, Trump, and Facebook Broke Democracy and How il Can Happen Again, HarperCollins, New york, 2019; tr. it. (edited by) C. Chiappa, La dittatura dei dati. La talpa di Cambridge Analytica svela come i big data e $i$ social vengono usati per manipolarci e minacciare la democrazia, HarperCollins, Milano, 2019.

3 Zuboff S., The Age of Surveillance Capitalism. The Fight for a Human Future at the New Frontier of

Power, Pubblic Affair, 2019; tr. it ed. by P. Bassotti, Il capitalismo della sorveglianza nell'era dei nuovi poteri, Luiss Press, Roma, 2019. This book collects Zuboff's studies that started in 2006 from interviews with entrepreneurs and employees of tech companies in the United States and the United Kingdom.

4 This book collects studies that began in 2006 by interviewing entrepreneurs and employees of commercial tech companies in the US and UK.
} 
And some questions at the beginning of the volume take us into the heart of the problem: can we call home the digital future? Meaning by home, regardless of its shape or location, the meaning of a place where we are known and can know others, where we are loved, where "to be free and flourish,.. take refuge and plan"s? And with what consequences on our lives?

"Home", writes the author, "is possession, voice, relationship, sanctuary". The right to a sanctuary is now undermined by digital capitalism. The feeling of the loss of one's home, that is, of one's own intimate dwelling, of the most vulnerable but precious place of one's life, causes feelings of nostalgia and disorientation.

This sense of loss presents us with a new horizon in which the digital world is taking over, redefining spaces, freedoms, goals, needs, without us being able to realize it in time and decide with courage and lucidity about who appropriates the human experience using it as a raw material to be transformed into data on behaviors.

As a new form of subtle and sophisticated despotism, data are used by agencies as predictive products about our future behaviors, information that allows to control a market, but also the space for political decision-making and legitimacy, and, therefore become a huge power. Predictive behavioral surplus sources are increased and enhanced to guide, advise and lead people to behaviors, which they believe free, which actually aim for the greater profit of surveillance capitalists.

So, a key point to keep in mind is that digital surveillance processes not only know and exchange information about our behaviors, but form them ${ }^{7}$. This is the most important and dangerous link: the transition from knowledge to power; better, knowledge as power: the information that concerns us becomes means of changing our behavior and knowledge of the world in which we live and act.

But where does most of the data come from about us? How are they processed and by whom? The method used by a famous agency, Cambridge Analytica, was very simple: thanks to the study of user data and the application of the theories of psychometrics drew extremely precise user profiles, based not on common interests but on common psychological traits (fear of, suspicious, extroverts etc. $)^{8}$. Once the user's profile was drawn up, the messages to be submitted were processed on the basis of the information collected thus exploiting needs, fears, beliefs 9 .

\footnotetext{
5 Zuboff S., op. cit., p. 15.

6 Ibidem.

7 See ibid., p. 18.

${ }^{8}$ At Cambridge Analityca the data were applied and used for psychographic analysis: a process according to which the scores assigned to the personality of each individual, object of the study, were applied to the database to try to understand the personalities of individuals, understand and plan what they were driven to act and decide. The team of analysts studied specific messages designed for certain personality types through a process called behavioral microtargeting. The evaluation system they created was named OCEAN. (Cfr. Kaiser, op. cit., pp. 104-105).

9 "In the process, I had been exposed to the vast sweep of Cambridge's efforts, both to acquire data on
} 
In Brittany Kaiser's book "The Data Dictatorship", the author, who joined the staff of political analysts at Cambridge Analytica ${ }^{10}$, reveals how big data and social media are used to manipulate and threaten democracy: "Today you don't need to knock on people's homes to find data. Data is everywhere. And they determine every decision". ${ }^{11}$.

The author follows the preparation of the team of analysts for the 2016 US presidential election and reveals all the processes and technologies to acquire information on a huge amount of individuals, to segment their profile and their moral, emotional, ideological orientations.

The goal is to set up a campaign of messages aimed at conditioning their behaviour, and, above all, their electoral decision.

From the electoral battle for the government of the states, we move on to the battle or the conflict to conquer global political and economic spaces through the conquest of information, and more extensively of ideas and knowledge.

Every cognitive war today is based on the use of data, information, news. In this context, we must consider the centrality of economic intelligence as both defensive and offensive, aimed at consolidating or achieving economic sovereignty without which freedom is only an illusion. In today's technological and geopolitical context, the nature and forms of conflict have also changed and taken completely new and sometimes devious forms and modalities.

Cognitive warfare ${ }^{12}$ is a form of war that does not involve physical violence but systematic manipulation of information to gain an advantage. Cognitive warfare also aims to build and make stable generalized mental representations, i.e. ideas and ways of thinking spread in public opinion that orient the emotions, attitudes, reasoning, choices and behaviors of the individuals ${ }^{13}$.

as many U.S. citizens as possible and to leverage that data to influence American's voting behavior. I'd also come to see how Facebook's negligent privacy policies and the federal government's total lack of oversight about personal data had enable all of Cambridge's efforts" (ibid., p. 8).

10 Cambridge Analytica (CA) was a British consultancy company whose name became famous following a data management scandal to influence election campaigns. The method used combined data mining, data intermediation and data analysis with strategic communication for the election campaign. Thanks to the combination of these disciplines with the study of psychometrics, the study of human behavior, Cambridge Analytica was able to exploit the psychological profile of users to identify a precise personality and pack extremely precise messages that were going to affect their weaknesses and fears. The method used by Cambridge Analytica was very simple: thanks to the study of user data and the application of the theories of psychometrics, he created extremely precise user profiles, based not on strands of common interests but on common psychological traits (fear of, suspicious, extroverts etc.). See, Wylie C., Mindf*: Inside Cambridge Analytica's Plot to Break the World, Profile Books, 2019.

${ }^{11}$ Kaiser B., op. cit., p. 87.

12 See, Gagliano G. (ed. by), Guerra economica, cognitiva, dell'informazione, goWare, Firenze, 2019.

13 See studies on Skinner's behavior: B.F. Skinner, About Behaviorism, Vintage, Ney York, 1976; Id., Science and Human Behavior, MacMillan, New York, 1953, (see you, Controlling Agencies, Section V, 
This concept is similar in many respects (not all, however) to that of information warfare, although it denotes a wider spectrum of meaning because it does not only includes conflicts between states.

Actors of cognitive warfare can be institutions (e.g. governments, government agencies, intelligence services), businesses, interest groups, individual citizens, which come into conflict with other institutions, businesses, interest groups, individual citizens on that battleground known as the public opinion.

Cognitive warfare is therefore concerned with producing or destroying elements of knowledge in a conflicting context, ranging in all fields that deal with communication processes, both in private and state dimension, not only dealing with disinformation, but also with conditioning knowledge as a whole.

Hence the misperception that cognitive warfare is not a form of conflict in all respects just because it does not resort to physical violence. [...]. Every cognitive conflict is, in a direct or indirect way, connected with economic control, and in particular with the capitalism of surveillance.

This type of war, is called by the Americans information warfare, and corresponds to cognitive warfare, in which the use of economic power tools through the web define power relationships without the use of weapons or other forms of war intervention.

In this new space and in the new logic of conflict, the instrument of information and disinformation or of deliberately provoked distortion, determine that information dominance that the experts of the new forms of online warfare talk about ${ }^{14}$.

But what new form of power is useful and functional to the cyberwars scenario?

The "instrumentalizing power", of which Zuboff speaks, which draws its strength by ignoring humanity and democracy, is putting our societies in front of a new form of power, connected to the capitalism of surveillance, which produces a "subversion from the top", leading to the belief that democracy is no longer an "inviolable necessity" and exploit its vulnerabilities to get the emptying of popular sovereignty: are we sovereigns without sceptre? The transition from soft power ${ }^{15}$ to

pp. 333- 415; and Section VI, Culture and Control); Id., To Know the Future, Behavior Analyst,13, n. $2(1990)$.

14 The aim is to exploit the target's perceptions and prejudices to distort their opinions, to induce behaviors and decisions that damage their own interests (see Kaiser B., op. cit). The main internet companies analyzed are: Apple, Google, Amazon, Microsoft and Facebook. But the focus is aimed at Facebook, Google and Microsoft, as American-based surveillance capitalism has now become a global reality.

15 Soft power (that can be translated with "sweet power" or "convincing power") is a term used in international relations theories to describe the ability of a political power to persuade, convince, attract and co-opt, through intangible resources such as "culture, values and institutions of politics". In the post Cold War era, soft power was one of the key concepts to analyze international relations. It represents the evolution of Gramsci's cultural hegemony combined with modern techniques, the ability to bring co-optation beyond coercion. Joseph Nye, author of the expression, showed that political hegemony is based on cultural hegemony rather than military power 
sharp power is a change of methodology and perspective in the new forms of power used.

Sharp power is "a new form of power: sharp, silent and dangerous", as Paul Messa writes ${ }^{16}$.

The concept of sharp power is quite new ${ }^{17}$ and therefore, we are facing a kind of computer revolution even in the modalities of the belligerence that brings political conflict into a digital space and dimension, acting on the ground of public opinion, politics and economics, culture and education. And above all, as the author points out, it is not only about large states such as China, Russia or the USA, but it affects all the great powers, including the emerging ones (the book sets the example of Iran) and the democratic ones, thus assuming a global nature. [...]

The developments of recent decades and the situation of crisis and permanent change that envelops international relations have led to the consideration of the existence of various nuances between the two extreme opposites. For a long time, in the last decade, there has been talk of "smart power". And now, coming out of the Western perspective, we're talking about "sharp power". A power, wrote the National Endowement for Democracy in the report in which the term was coined, "that like a sharp knife pierces, penetrates or perforates the media and political context in the countries targeted".

Let's start with an important premise: sharp power is a concept born in the US and developed in the Euro-Atlantic field to define the attempts of infiltration, influence and conditioning carried out by rival countries of the United States in particular, to undermine, according to analysts who support the use of the concept, the solidity among the allies of NATO.

The Sharp power, sharp and cutting, is the mirror of the era of permanent instability in which we are living ${ }^{18}$.

The first side of the sharp power concerns the field of information, data and

16 Messa P., L'era dello sharp power. La guerra (cyber) al potere, Università Bocconi Editore, 2018.

Paolo Messa declares his point of view as that of a strong supporter of NATO and of the leading role of the United States who perceives assertiveness in sharp power battlefield as a threat from countries considered as rivals: firstly China and Russia and, in a second line, Iran.

17 It was first expressed in 2017 by the National Endowment for Democracy (Ned), a US non-profit foundation that in its long relationship Sharp Power. Rising Authoritarian Infuence stated that illiberal regimes would try to interfere in the life of democratic countries by taking advantage of the new tools offered by globalization: manipulation of news, pressure on political and economic actors, cyber attacks. (See, Messa P., op. cit., pp. 45-46).

18 Sharp power is first expressed in 2017 by the National Endowment for Democracy (Ned), a U.S. nonprofit foundation that in its long-term report "Sharp Power. Rising Authoritarian Infuence" denounced the actions of states such as Russia and China aimed at promoting a silent but effective propaganda work abroad to increase their influence. According to the report, illiberal regimes would attempt to interfere in the lives of democratic countries by exploiting in their favour the new tools offered by globalisation: manipulation of news, pressure on political and economic actors, cyber attacks. 
frontier technologies. The other side, complementary to it, is the action in cyberspace, the intelligence conflict that is fought for control of that information ${ }^{19}$.

It will be the future of force relationships in the cyber front that will determine the outcome of the battle in which sharp power fits.

It is necessary to add a consideration on sharp power to classify it as a possible modern reinterpretation of the traditional technique to disorientate the antagonist, to undermine his certainties, to weaken his determination.

Finally, the age of sharp power reminds us that the substantial element of today's international context is complexity. Complexity that also breaks down geopolitical rivalries, now no longer destined to continue on traditional tracks, but increasingly fought below sea level or, even better, in the virtual depths of cyberspace.

Using the author's words, we are facing a "revolution in the science of international relations". A cyber revolution that brings political conflict into a digital dimension, acting on the ground of public opinion, politics and economy. And that, above all, as the author points out, doesn't concern only China and Russia, but it affects all the great powers, including the emerging ones (the book sets the example of Iran) and the democratic ones, thus assuming a global nature.

As the author writes, the era of sharp power like a sharp knife pierces the media and political context in the countries targeted. The fight for global leadership, using fake news, manipulation and control, presume cyberspace as a theatre of crucial importance: here are now facing each other not only troll groups and hackers with the silent consent of the reference governments, but also real military units created ad hoc. A digital and information-only war that, this volume highlights, also threatens our country ${ }^{20}$.

And is Italy threatened by this digital war? Paolo Messa also delves into this theme, widening the field of interest to the network of influence of Russia and China in Italy. The first country is always present in the Italian political debate, but about the second, according to the author, there's too little talk. But I don't think I'm going to dwell on that now.If, therefore, the internet is the battleground for cognitive warfare, or information, or digital war, the areas involved are now all fields of social, political and economic life, investing the world of social representations, of collective imagination, of priorities and purposes of those who govern and of those who decide who must govern, that is, the sovereign people.

But as Hannah Arendt's current and acute analysis shows, totalitarianism has various forms. And today presents itself with the claim of a total domination of data, digital technology and cyberspace which effectively defies the control of the law: no

19 "The cyber revolution", writes F. Bechis in the Introduction to Messa book, "has radically changed the rules of the game, opening a new front where it is difficult to distinguish lone wolves from military units of their respective countries. Spies in suits, tie and briefcase have given way to the much more effective cyber espionage" (Bechis F., in Messa P., op. cit., p. 4).

20 Ibid., pp. 31-47. 
concern for totalitarianism for the positive law of states, - Hannah Arendt writes "claims to be a superior form of legitimacy that can do without legality; and despising legality, the totalitarian regime claims to implement the law of history or nature without translating it into principles of just and unjust for individual behavior"21.

But I could add the thought of George Orwell when in 1984 he indicated how Big Brother was eliminating all forms of cultural, psychological, linguistic and emotional resistance in individuals to completely submit them to the Prolet, to the Party ${ }^{22}$.

Every project of subversion of freedom and democratic justice uses the manipulation of information, the erasure of historical memory, the control of social bonds, the levers of fear and insecurity.

Without systems of control and protection of human rights, there is no possibility of defense against those who pursue only the unlimited profit of the few at the expense of the manipulation and mystification of many, and there can be no true democracy. And, without the possibility of distinguishing truth from lies, the confusion between what is true and what is false plays in favor of the capitalists of digital surveillance and of the strategy of sharp power.

Zuboff speaks of "instrumentalizing ideology": this "instrumentalizing power" has in the digital connection the sole purpose of commercial power over the lives of individuals, who are citizens and therefore make political choices. This insatiable monster is "self-referential and parasitic": if Marx defined capitalism as a vampire that feeds on work, the capitalism of digital surveillance "feeds on every aspect of human life"23.

In addition, data processing and market control techniques, as well as cognitive conflict, exploits an unprecedented asymmetry between knowledge and power: they know everything about us and we know nothing about them; they do everything at our expense and not for us, they predict our future so that there is gain for someone, but not for us, with deep consequences for our lives and democracies.

What must be distinguished are the purposes of the surveillance capitalists from the technologies they employ: the purpose from the medium. Don't confuse the puppeteer with the puppets: "the economic imperatives of surveillance capitalism are the puppeteers hidden behind the scenes who manage the machines and put them into action" 24 .

\footnotetext{
${ }^{21}$ Arendt H., The Origins of Totalitarianism, A Harverst Book- Harcourt, Inc., New York, 1966, p. 632.

22 Orwell G., Nineteen eighty-four, Harcourt, New York, 1949. Orwell portrays a terrifying vision of life in the future when a totalitarian government, considered a "Negative Utopia", watches over all citizens and directs all activities, becoming more powerful as time goes by.

23 See, Zuboff, S., op. cit., pp. 433- 435. See also, the death of individualism and the rendering of social relationships (ibid., cap. 15).

24 Surveillance capitalism "is not a technology, but a logic that permeates technology and transforms it into action". This distinction is fundamental in order not to confuse "puppets with puppeteer" (ibid., pag. 25).
} 
Let us go back to the old problem of the relationship between technology, political power and the purposes of human action. But with the need for new questions.

Finally, are the operations of surveillance capitalism a challenge to the natural right to the future? Are they a threat to everyone's ability to imagine, decide, promise and build a future?

\section{Conclusion}

The rise of the instrumentalizing power, of the "Great Other" 25 , and the deeply undemocratic new vision of society and the resulting social relations, presents itself as a grab of the power from the top through an overthrow not of the state but of individual sovereignty.

My aim is stimulating a reflection about the relationship between freedom and the sovereignty of citizens and the risks to democracy of our time. Protection from data hegemony and those who use it for the control of our lives is the necessary condition for true democracy, and it also shows the vulnerability of our lives, traced or conditioned through global digitization.

Finding tools and forms of cultural awareness to protect people from the conditioning of their political, cultural and ethical choices through digital power is a fundamental problem of our democracies to which we must give greater importance and attention.

In other words, are we facing a strong and unassailable conditioning to our free will to want? And are we facing a planned depletion of popular sovereignty, the heart of democracy?

How can we defend ourself from a sharp and cutting power? How can we remain masters of our living space and of our knowledge of the world? How can we avoid the control of the digital surveillance Lords? The problem is open.

Our right to the future is in danger, that "right to a sanctuary" ${ }^{26}$ as a space that can be an inviolable refuge of the mental, moral and social life of every citizen.

But if the digital future really is going to be our home, then it is up to us to make it habitable and human. The good of humanity must be put back at the centre of the information civilization: here the ethical system of the present world and the future world is fully endangered. And we need to invest in culture by involving institutions, free citizen associations, transparent organisations aimed at making justice and freedom.

A commitment of great complexity that clashes against giant powers and interests; But is it a challenge we can win? I like to respond with the words of Max Weber: "The possible would not be achieved if in the world we did not try the impossible".

25 I use the definition in Zuboff S., op. cit., pp. 393-414.

26 Ibid., p. 31. 


\section{Reference}

1. Albagli S., Maciel M.L. (Ed. by), Information, Power and Politics Technological and Institutional Mediations, Lexington Book, UK, 2010.

2. Arendt H., The Origins of Totalitarianism, A Harverst Book- Harcourt, Inc., New York, 1966, p. 632.

3. Betancourt M., The Critique of Digital Capitalism: An Analysis of the Political Economy of Digital Culture and Technology, punctum books, 2015.

4. Gagliano G. (ed. by), Guerra economica, cognitiva, dell'informazione, goWare, Firenze, 2019.

5. Latouche S., La mégamachine: raison technoscientifique, raison économique et mythe du progrès, La Découverte, 1995; tr. it., La megamacchina: ragione scientifica, ragione economica e mito del progresso, Bollati Boringhieri, 1995.

6. Kaiser, B., Targeted: The Cambridge Analytica Whistleblower's Inside Story of How Big Data, Trump, and Facebook Broke Democracy and How il Can Happen Again, HarperCollins, New York, 2019.

7. Messa P., L'era dello sharp power. La guerra (cyber) al potere, Università Bocconi Editore, 2018.

8. Nagle A., Contro la vostra realtà. Come l'estremismo del web è diventato mainstream, Luiss University Press, 2018.

9. Ohlin J. D., Govern K., C. Oakes Finkelstein (edited by), Cyberwar, Law and Ethics for Virtual Conflicts, Oxford University Press, 2015.

10. Orwell G., Nineteen eighty-four, Harcourt, New York, 1949.

11. Qiao L., Wang X., Guerra senza limiti. L'arte della guerra asimmetrica fra terrorismo e globalizzazione, LEG, 2004.

12. Skinner B.F., Science and Human Behavior, MacMillan, New York, 1953, pp. 333- 415.

13. About Behaviorism, Vintage, Ney York, 1976.

14. To Know the Future, Behavior Analyst, 13, n. 2 (1990).

15. Vattimo G., Nichilismo ed emancipazione, Garzanti, Milano, 2003.

16. D. Walker C., What is "Sharp Power"?, Journal of Democracy, v. 29, number 3, July 2018, pp. 9-23.

17. Wylie C., Mindf*: Inside Cambridge Analytica's Plot to Break the World, Profile Books, 2019.

18. Zuboff S., The Age of Surveillance Capitalism. The Fight for a Human Future at the New Frontier of Power, Pubblic Affair, 2019; tr. it ed. by P. Bassotti, Il capitalismo della sorveglianza nell'era dei nuovi poteri, Luiss Press, Roma, 2019 . 